\title{
LIXIVIAÇÃO DE POTÁSSIO DA PALHA DE ESPÉCIES DE COBERTURA DE SOLO DE ACORDO COM A QUANTIDADE DE CHUVA APLICADA ${ }^{(1)}$
}

\author{
C. A. ROSOLEM(2), J . C. CALONEGO ${ }^{(3)} \&$ J . S. S. FOLONI ${ }^{(4)}$
}

\begin{abstract}
RESUMO
Os restos vegetais dei xados na superfície do solo em sistemas de semeadura direta, além de proteger o solo da erosão, constituem considerável reserva de nutrientes que podem ser disponibilizados para a cultura princi pal, subseqüente. Avaliou-se a lixiviação de $K$ da palha de seis espécies vegetais com potencial de uso como plantas para cobertura do solo de acordo com a quantidade de chuva recebida após o manejo. Milheto (Pennisetum americanum, var. BN-2), sorgo de gui né (Sorghum vulgare), aveia preta (Avena strigosa), triticale (Triticum secale), crotalária juncea (Crotalaria juncea) e braquiária (Brachiaria decumbens) foram cultivados em vasos com terra, em casa de vegetação, em Botucatu (SP). Aos 45 dias da emergência, as plantas foram cortadas na altura do colo, secas em estufa e submetidas a chuvas simuladas de 4,4, 8,7, 17,4, 34,9 e 69,8 mm, considerando uma quantidade de palha equivalente a $8,0 \mathrm{t} \mathrm{ha}^{-1}$. A máxima retenção de água pela palha corresponde a uma lâmina de até $3,0 \mathrm{~mm}$, independentemente da espécie, praticamente não ocorrendo lixiviação do potássio com chuvas da ordem de $5 \mathrm{~mm}$. A máxima li beração de $\mathrm{K}$ por unidade de chuva ocorre com lâmi nas de até $20 \mathrm{~mm}$, decrescendo a partir deste ponto. A quantidade de $\mathrm{K}$ liberado da palha logo após o manejo depende da espécie vegetal, não ultrapassando, no entanto, $24 \mathrm{~kg} \mathrm{ha}^{-1}$ com chuvas da ordem de $70 \mathrm{~mm}$, apresentando correlação positiva com a concentração do nutriente no tecido vegetal. 0 triticale e a aveia são mais eficientes na ciclagem do potássio.
\end{abstract}

Termos de indexação: ciclagem de nutrientes, cobertura morta, precipitação, semeadura direta.

\footnotetext{
(1) Recebido para publicação em julho de 2002 e aprovado em janeiro de 2003.

(2) Professor Titular do Departamento de Produção Vegetal, Faculdade de Ciências Agronômicas, Universidade Estadual Paulista UNESP. Caixa Postal 237, CEP 18603-970 Botucatu (SP). Bolsista do CNPq. E-mail: rosolem@fca.unesp.br

(3) Acadêmico de Agronomia, Faculdade de Ciências Agronômicas, UNESP. Bolsista da FAPESP.

(4) Doutorando do Curso de Pós-Graduação em Agricultura, Faculdade de Ciências Agronômicas, UNESP, Bolsista da FAPESP. E-mail: sfoloni@fca.unesp.br
} 


\title{
SUMMARY: POTASSIUM LEACHING FROM GREEN COVER CROP RESIDUES AS AFFECTED BY RAINFALL AMOUNT
}

\begin{abstract}
Besides protecting soil from erosion, plant residues left on the soil surface by green cover crops in no-till cropping systems represent a considerablenutrient source of nutrients that can bemadeavailablefor thefoll owing crop. Potassi um leaching from thestraw of six cover crop species was evaluated, in relation to the amount of rain on the residues. Pearl millet (Pennisetum americanum), guinea sorghum (Sorghum vulgare), black oat (Avena strigosa), triticale (Triticum secale), Indian hemp (Crotalaria juncea) and brachiaria (Brachiaria decumbens) were grown under greenhouse conditions in pots with soil, in Botucatu, State of São Paulo, Brazil. F orty-five days after emergence, the plants were cut, dried and placed in PVC rings, simulating an amount of $8 \mathrm{t} \mathrm{ha}^{-1}$ of straw. Rainfalls of 4.4, 8.7, 17.4, 34.9, and $69.8 \mathrm{~mm}$ were applied. The straws retained up to $3.0 \mathrm{~mm}$ of water, irrespective of the plant species, and rains of $5 \mathrm{~mm}$ did not cause $\mathrm{K}$ leaching. Maximum $\mathrm{K}$ leaching per rain unit was observed for rainfalls around $20 \mathrm{~mm}$, and decreased under heavier rainfalls. The amount of $\mathrm{K}$ released from the straw right after preparation is speciesdependent, but is al ways bel ow $24.0 \mathrm{~kg} \mathrm{ha}^{-1}$ under rains up to $70 \mathrm{~mm}$, and positively related with tissue nutrient contents. Triticale and black oats are more efficient at recyding $\mathrm{K}$.
\end{abstract}

Index terms: cover crops, no-till, nutrient cycling, rains.

\section{INTRODUÇÃO}

A manutenção de restos vegetais na superfície do solo em sistemas de produção agrícola com semeadura direta, além de proteger o solo da radiação solar, dissipa a energia de impacto das gotas de chuva, reduz a evaporação de água e ajuda no controle de plantas daninhas (Gassen \& Gassen, 1996), consistindo ainda em reserva de nutrientes considerável, cuja disponibilização pode ser rápida e intensa, dependendo, dentre outros fatores, do regime de chuvas.

Depois do nitrogênio, o potássio é o nutriente mi neral requeridoem mai or quantidade pelas espécies vegetais. Este nutriente tem alta mobilidade na planta, em qualquer nível de concentração, seja dentro da célula, no tecido vegetal, seja, ainda, no xilema e floema (Malavolta, 1980). O cátion K+não é metabolizado na planta e forma ligações com complexos orgânicos de fácil reversibilidade. É o cátion mais abundante no citoplasma das células vegetais ea sua maior contribuição no metabolismo das plantas está relacionada com o controle do potencial osmótico das células e dos tecidos (Marschner, 1995). A transl ocação deK nas plantas é facilitada pelo fato de mais de $80 \%$ dele estar presente nos tecidos vegetais em forma solúvel. No final do ciclo do milho, por exemplo, a quantidade de $K$ presente no tecido é muito menor do que na fase de máximo acúmulo deste nutriente. I sso decorre, provavel mente, da lavagem do K da parte aérea das plantas. Essa lavagem de nutrientes das plantas tem um significado ecológico importante, pois intensifica a reciclagem ea fertilização das camadas superficiais do solo (Malavolta, 1980).
A facilidade de extração de $K$ do tecido vegetal foi descrita por Moraes \& Arens (1969), que constataram ser o K facilmente lavado das fol has de plantas cultivadas, quando estas são imersas em água destilada, mostrando que o fenômeno pode ocorrer em condições de campo graças à ação da água do orval ho ou das chuvas.

Cottica et al. (1999), avaliando a decomposição e a concentração de nutrientes na palha de aveia preta ao longo do tempo, observaram que, passados 55 dias do manejo da cultura, o conteúdo de $\mathrm{K}$ da palha havia diminuído em $92 \%$. O mesmo método foi utilizado por Marcon et al. (1999) para avaliar a liberação de nutrientes de restos vegetais de nabo forrageiro; esses autores constataram que, após 53 dias do manejo das plantas, o conteúdo de $\mathrm{K}$ diminuiu em $99 \%$.

Rosolem (1997) relatou, por outro lado, que os programas de adubação potássica no Brasil foram desenvolvidos, basicamente, para condições em que se utiliza o preparo convencional do solo, concluindo que, no caso da semeadura direta em sistemas de produção com rotação de culturas, um dos pontos a ser considerado diz respeito à quantidade de $\mathrm{K}$ acumulado na pal ha da superfície do solo, bem como à disponibilidade desta fonte do nutriente ao longo do tempo, ou seja, à intensidade de recidagem do potássio.

Considerando a necessidade de aprimorar os conhecimentos sobre a disponibilidade de $\mathrm{K}$ em condições de semeadura direta, com palha na superfície, desenvolveu-se o presentetrabal ho para avaliar, comparativamente, a lixiviação de K dos restos de seis espécies vegetais usadas como plantas de cobertura do solo, de acordo com a quantidade de chuva recebida após o manejo. 


\section{MATERIAL E MÉTODOS}

O experimento foi realizado, em 2001, em casa de vegetação, na Faculdade de Ciências Agronômicas, Botucatu (SP). Utilizou-se a camada superficial (0$20 \mathrm{~cm}$ ) de um Latossolo Vermelho distroférrico de textura média (E MBRAPA, 1999). O material, após secagem ao ar, foi passado em peneira com malha de $2 \mathrm{~mm}$ e homogeneizado. Foram tomadas amostras para análises químicas (Raij \& Quaggio, 1983), granulométricas (EMBRAPA, 1997) e para determinação do teor de água na capacidade de campo (EMBRAPA, 1997). Os resultados estão apresentados no quadro 1.

A pós o tratamento inicial, o sol o foi corrigido com cal cário dol omítico (CaO: $28 \%$, MgO: $20 \%$ e PRNT: 95 \%) para el evar a saturação por bases a 70 \% (Raij et al., 1996). A terra foi umedecida à capacidade de campo e acondicionada em sacos plásticos por 30 dias. Em seguida, foi seca ao ar e adubada com $100 \mathrm{mg} \mathrm{dm}^{-3}$ de N (Uréia), $200 \mathrm{mg} \mathrm{dm}^{-3}$ de P (Superfosfato Simples) e $150 \mathrm{mg} \mathrm{dm}^{-3}$ de K (Cloreto de Potássio).

Foram cultivados milheto (Pennisetum americanum, var. BN-2), sorgo de guiné (Sorghum vulgare), aveia preta (Avena strigosa), triticale (Triticum secale), crotalária juncea (Crotalaria juncea) e braquiária (Brachiaria decumbens). As sementes foram pré-germinadas em laboratório, para mi nimizar as variações detempo deemergência existentes entre as espécies. A pós a emergência das

Quadro 1. Características físicas e químicas da camada superficial do Latossolo Vermelho distroférrico utilizado no experimento

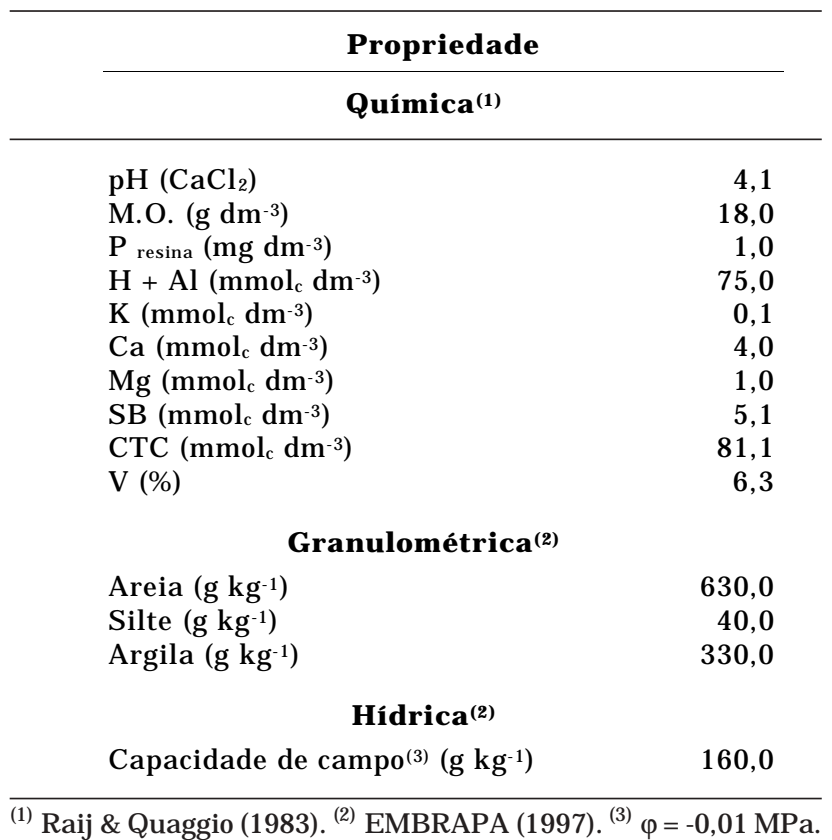

plântulas, fez-se um desbaste, deixando-se 50 plantas por vaso. A temperatura da casa de vegetação foi mantida entre 20 e $25^{\circ} \mathrm{C}$ e a umidade relativa do ar entre 70 e $90 \%$ durante o período experimental.

Os vasos continham $30,8 \mathrm{dm}^{3}$ deterra. O teor de água foi monitorado diariamentee corrigi do sempre que necessário para que permanecesse próximo à capacidade de campo. Do 20 o ao 25o dia da emergência das plântulas, fizeram-se adubações suplementares nos vasos por meio da água de irrigação, com macro e mi cronutrientes, totalizando $100,50,50,25,25$ e 53,3 mg dm ${ }^{-3}$ de N, P, K, Ca, Mg e $\mathrm{S}$, respectivamente, com os sais $\mathrm{N} \mathrm{H}_{4} \mathrm{NO}_{3}$, $\mathrm{NH}_{4} \mathrm{H}_{2} \mathrm{PO}_{4}, \mathrm{KNO}_{3}, \mathrm{CaSO}_{4} \mathrm{eMgSO}_{4}$. Osmicronutrientes adicionados foram $\mathrm{B}, \mathrm{Zn}, \mathrm{Mo}, \mathrm{Mn}$ e $\mathrm{Cu}$ na dose de $1 \mathrm{mg} \mathrm{dm}^{-3}$, por meio do uso das fontes $\mathrm{H}_{3} \mathrm{BO}_{3}, \mathrm{ZnCl}_{2}$, $\mathrm{H}_{2} \mathrm{MoO}_{4}, \mathrm{MnCl}_{2} \mathrm{eCuCl}_{2}$, respectivamente.

No 45o dia de cultivo, fez-se a coleta da parte aérea das plantas. O material vegetal foi fracionado em pedaços de 3 a $5 \mathrm{~cm}$ e desidratado em estufa de aeração forçada por cinco dias a $35^{\circ} \mathrm{C}$. Após a desidratação, as palhas foram acondicionadas em sacos plásticos e mantidas sob refrigeração, para posterior utilização no simulador de chuvas. Retiraram-se subamostras dessas palhas para nova secagem a $60^{\circ} \mathrm{C}$, até atingirem massa constante, para se aferir a quantidade de pal ha seca a $35^{\circ} \mathrm{C}$ a ser utilizada no processo de simulação de chuvas, equivalente a uma cobertura do solo de $8 \mathrm{t} \mathrm{ha}^{-1}$ de matéria vegetal seca a $60^{\circ} \mathrm{C}$. Parte do material seco a $60{ }^{\circ} \mathrm{C}$ foi reservada para determinação dos teores de K (Malavolta et al., 1997).

O simulador de chuvas utilizado no experimento (Figura 1) foi descrito detalhadamente por Silva (2000). A barra de suporte dos bicos pulverizadores foi fixada a 1,45 m acima das palhas. Utilizaram-se cinco bicos de alta vazão, da marca Spray System, modelo TK-SS-20, sendo o espaço entre bicos de $50 \mathrm{~cm}$. O tracionamento do sistema de pulverização foi feito por meio de correias e engrenagens, acionadas por motores elétricos, mantendo-se constante a velocidade de deslocamento da barra previamente determinada por um modulador de freqüência. A quantidade de chuva aplicada a cada desl ocamento da barra foi determinada por meio de testes, sendo o equipamento cali ibrado para aplicar um vol ume de água equivalentea 4,4 $\mathrm{mm}$. As gotas de chuva produzidas pelo simulador foram geradas utilizando-se uma pressão de trabalho de 81,0 Pa, com velocidade de deslocamento da barra de pulverização de $0,0526 \mathrm{~m} \mathrm{~s}^{-1}$.

As quantidades de chuva aplicadas foram equivalentes a 4,4, 8,7, 17,4, 34,9 e 69,8 mm, sendo necessário executar 1, 2, 4, 8 e 16 desl ocamentos da barra de pulverização, respectivamente. A cada aplicação havia deslocamento da barra numa distância de 3,0 m, em $5 \mathrm{~min}$. Este procedimento não permite o cálculo da intensidade de chuva em 


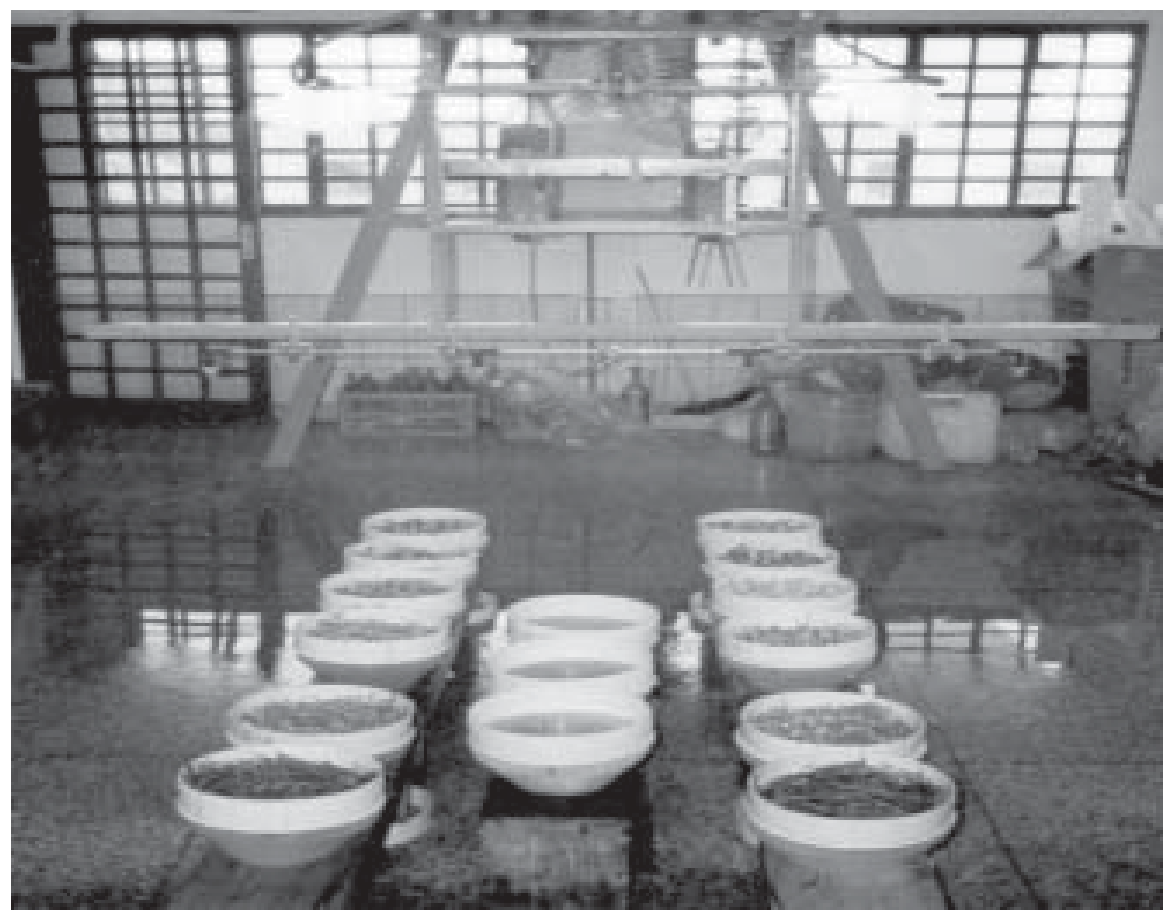

Figura 1. Simulador de chuva utilizado no experimento, mostrando a distribuição dos vasos.

$\mathrm{mm} \mathrm{h}^{-1}$, pois o equipamento aplica pulsos de água a interval os regulares (a cada passagem), de modo que a intensidade é alta no momento da aplicação, mas existe um intervalo de repouso entre aplicações a cada vaso, de, aproximadamente 6 min, contandose o tempo de aplicação e o retorno da barra.

As palhas que receberam a água da chuva foram colocadas em anéis de PVC rígido com área superficial de 0,049 $\mathrm{m}^{2}$, altura de 0,10 m e telados ao fundo com fios de nylon com malha de $10 \mathrm{~mm}$. Cada anel recebeu 39,27 g de palha, equivalente a $8 \mathrm{t} \mathrm{ha}^{-1}$, calculados com basena área. Os anéis foram fixados em funis plásticos, ea água, após passar pelas palhas, foi col etada em recipientes posicionados sob cortina plástica. As estruturas que continham as palhas foram colocadas em pontos eqüidistantes ao longo do percurso de deslocamento da barra. As palhas de cada espécie avaliada, de acordo com o delineamento experimental adotado, foram colocadas em quatro anéis distribuídos em blocos. Foram colocados também quatro anéis sem palha em todas as aplicações de chuva para determi nação doK da água utilizada na simulação. O procedimento adotado foi baseado em método desenvolvido por Maciel (2001), mais testes preliminares.

Ao final de cada aplicação de chuva, a água que passou pelas palhas teve o seu vol ume determinado, tendo sido filtrada e mantida sob refrigeração $\left(2^{\circ} \mathrm{C}\right)$. Determinou-se também a massa das palhas umedecidas, imediatamente após cada processo de simulação. Com as massas da palha seca e úmida foi possível calcular a quantidade de água retida, que foi transformada em $\mathrm{mm}$, considerando a área do anel. As palhas que sofreram lavagem foram secas em estufa a $60^{\circ} \mathrm{C}$ e tiveram os teores de $\mathrm{K}$ medidos (Malavolta et al., 1997). Determinaram-se também as concentrações de $\mathrm{K}$ da água percolada, por meio do equipamento "I nductively Coupled Plasma", cujos valores foram convertidos para kg ha-1, com base na área dos anéis.

O delineamento experimental utilizado foi o de blocos ao acaso, em um esquema fatorial $(6 \times 5)$, sendo constituído das palhas de seis espécies vegetais cultivadas em quatro repetições submetidas a cinco níveis de chuva simulada. O estudo estatístico constou de análise de variância e ajuste de equações matemáticas, para expressar adequadamente o comportamento dos resultados obtidos, sendo escol hidas as significativas de melhor ajuste. Utilizando a primeira derivada da equação ajustada aos dados de lixiviação acumulada de K, calculou-sea taxa de lixiviação, ou seja, a quantidade de $\mathrm{K}$ lixiviado por $\mathrm{mm}$ de chuva.

\section{RESULTADOS E DISCUSSÃO}

F oram constatadas interações significativas entre os fatores espécie vegetal e lâmina de chuva para retenção de água na palha, $\mathrm{K}$ lixiviado e lixiviação acumulada deK. Os parâmetros das equaçõesajustadas, bem como os coeficientes de determinação $\left(R^{2}\right)$ das análises de regressão, encontram-se no quadro 2. 
Quadro 2. Parâmetros e coeficientes dos modelos matemáticos de regressão utilizados nas análises dos dados experimentais

\begin{tabular}{|c|c|c|c|c|c|}
\hline \multirow{2}{*}{ Espécie } & \multicolumn{5}{|c|}{ Parâmetro } \\
\hline & $\mathbf{a}$ & b & C & d & $\mathbf{R}^{2}$ \\
\hline & \multicolumn{5}{|c|}{$\begin{array}{l}\text { Variável } \mathrm{y}_{1} \text { : Retenção de água na palha(1), em mm. } \\
\text { Equação } \mathrm{y}_{1}=\mathrm{ax} /(\mathrm{b}+\mathrm{x})+\mathrm{cx}\end{array}$} \\
\hline $\begin{array}{l}\text { Braquiária } \\
\text { Milheto } \\
\text { Sorgo } \\
\text { Crotalária } \\
\text { Triticale } \\
\text { Aveia-preta }\end{array}$ & $\begin{array}{l}1,86 \\
1,59 \\
1,77 \\
1,75 \\
2,65 \\
2,81\end{array}$ & $\begin{array}{l}1,62 \\
0,86 \\
0,69 \\
0,31 \\
1,66 \\
1,17\end{array}$ & $\begin{array}{l}0,010 \\
0,006 \\
0,006 \\
0,008 \\
0,005 \\
0,005\end{array}$ & $\begin{array}{l}- \\
- \\
- \\
- \\
- \\
-\end{array}$ & $\begin{array}{l}0,999 \\
0,999 \\
0,999 \\
0,998 \\
0,996 \\
0,994\end{array}$ \\
\hline & \multicolumn{5}{|c|}{$\begin{array}{l}\text { Variável } \mathrm{y}_{2} \text { : Potássio lixiviado por mm de chuva(2), em } \mathrm{kg} \mathrm{ha}^{-1} \mathrm{~mm}^{-1} \\
\text { Equação } \mathrm{O}_{2}: \mathrm{y}_{2}=\mathrm{a}+\mathrm{b}^{*} \ln \mathrm{n}+\mathrm{c}^{*}(\ln \mathrm{x}){ }^{\wedge}+\mathrm{d}^{*}(\ln \mathrm{x})^{\wedge} 3\end{array}$} \\
\hline $\begin{array}{l}\text { Braquiária } \\
\text { Milheto } \\
\text { Sorgo } \\
\text { Crotalária } \\
\text { Triticale } \\
\text { Aveia-preta }\end{array}$ & $\begin{array}{l}2,50 \\
3,68 \\
1,33 \\
0,76 \\
3,51 \\
3,74\end{array}$ & $\begin{array}{l}-0,80 \\
-1,20 \\
-0,42 \\
-0,22 \\
-1,05 \\
-1,15\end{array}$ & $\begin{array}{l}0,08 \\
0,12 \\
0,04 \\
0,02 \\
0,10 \\
0,11\end{array}$ & $\begin{array}{l}-2,16 \\
-3,12 \\
-1,15 \\
-0,67 \\
-3,11 \\
-3,27\end{array}$ & $\begin{array}{l}0,986 \\
0,983 \\
0,998 \\
0,999 \\
0,998 \\
0,998\end{array}$ \\
\hline & \multicolumn{5}{|c|}{$\begin{array}{l}\text { Variável } y_{3}: \text { Lixiviação acumulada de potássio(3), em kg ha-1. } \\
\text { Equação }{ }^{(3)} y_{3}=a+b x^{\wedge} c /\left(d^{\wedge} c+x^{\wedge} c\right)\end{array}$} \\
\hline $\begin{array}{l}\text { Braquiária } \\
\text { Milheto } \\
\text { Sorgo } \\
\text { Crotalária } \\
\text { Triticale } \\
\text { Aveia-preta }\end{array}$ & $\begin{array}{l}95,10 \\
98,52 \\
42,91 \\
18,89 \\
58,34 \\
50,18\end{array}$ & $\begin{array}{l}0,17 \\
0,23 \\
0,29 \\
0,79 \\
0,63 \\
0,57\end{array}$ & $\begin{array}{c}86,04 \\
0,46 \\
488,7 \\
62,05 \\
33,60 \\
12,27\end{array}$ & $\begin{array}{r}-35,75 \\
-61,05 \\
-8,60 \\
-1,89 \\
-12,21 \\
-17,62\end{array}$ & $\begin{array}{l}0,999 \\
0,999 \\
0,999 \\
0,999 \\
0,999 \\
0,998\end{array}$ \\
\hline & \multicolumn{5}{|c|}{$\begin{array}{l}\text { Variável } y_{4} \text { : Percentagem acumulada de potássio lixiviado(4), em \%. } \\
\text { E quação4: } y_{4}=a+b x^{\wedge} c /\left(d^{\wedge} c+x^{\wedge} c\right)\end{array}$} \\
\hline $\begin{array}{l}\text { Braquiária } \\
\text { Milheto } \\
\text { Sorgo } \\
\text { Crotalária } \\
\text { Triticale } \\
\text { Aveia-preta }\end{array}$ & $\begin{array}{l}57,85 \\
54,21 \\
27,95 \\
13,72 \\
14,69 \\
17,22\end{array}$ & $\begin{array}{l}0,17 \\
0,23 \\
0,29 \\
0,79 \\
0,63 \\
0,57\end{array}$ & $\begin{array}{c}86,04 \\
0,46 \\
488,7 \\
62,05 \\
33,60 \\
12,27\end{array}$ & $\begin{array}{r}-21,75 \\
-33,59 \\
-5,60 \\
-1,37 \\
-3,08 \\
-6,05\end{array}$ & $\begin{array}{l}0,999 \\
0,999 \\
0,999 \\
0,999 \\
0,999 \\
0,998\end{array}$ \\
\hline
\end{tabular}

(1) Figura 2. ${ }^{(2)}$ Figura 3. ${ }^{(3)}$ Figura 4. ${ }^{(4)}$ Figura 6. x = lâmina aplicada (mm).

Quanto à quantidade de água retida na palha, é possível dividir as espécies vegetais estudadas em dois grupos: triticale e aveia preta, com maior retenção de água, e sorgo, milheto, crotalária e braquiária, com menor retenção (Figura 2). Com base nos resultados do presente trabalho, não é possível estabelecer hipóteses que expliquem este comportamento diferencial. Entretanto, se forem consi deradas condições de campo, as diferenças são de pequeno significado prático, pois a retenção de água pelas palhas não passou de $3 \mathrm{~mm}$.

Nota-se que lâminas dechuva ao redor de $5,0 \mathrm{~mm}$ não foram suficientes para liberar quantidades significativas de potássio, chegando, no máximo, a $100 \mathrm{~g} \mathrm{ha}^{-1} \mathrm{~mm}^{-1}$ de $\mathrm{K}$ (Figura 3 ), sendo esta quantidade maior nas pal has das espécies que mais retiveram água por unidade de chuva. Assim, a quantidade de água retida pelas palhas não parece ser um fator determinante na lixiviação do nutriente.
Para uma chuva de $8,7 \mathrm{~mm}$, foi observada a maior liberação de K do milheto, sorgo e braquiária. Para as demais espécies, a máxima li beração do nutriente ocorreu com a chuva de 17,4 mm. Verificou-se, ainda, que, a partir de $17,4 \mathrm{~mm}$, a extração do nutriente por $\mathrm{mm}$ de chuva caiu gradativamente a cada incremento no volume de precipitação. É importante ressaltar que se está discutindo quantidade de chuva e não intensidade, pois, por exemplo, a quantidade de $17,4 \mathrm{~mm}$, na realidade, corresponde a 4 pulsos de $4,4 \mathrm{~mm}$.

$\mathrm{O}$ triticale e a aveia preta liberaram mais $\mathrm{K}$ por unidade de chuva que as demais espécies (quantidades da ordem de 600 a $650 \mathrm{~g} \mathrm{ha}^{-1} \mathrm{~mm}^{-1}$ ), mas exigiram mais água para tal (Figura 2). O milheto e a braquiária liberaram o K com maior facilidade, mas em menor quantidade (de 500 a $300 \mathrm{~g} \mathrm{ha}^{-1} \mathrm{~mm}^{-1}$ ), enquanto o sorgo e a crotalária liberaram menos $\mathrm{K}$ do que as demais espécies a cada mm de chuva. 


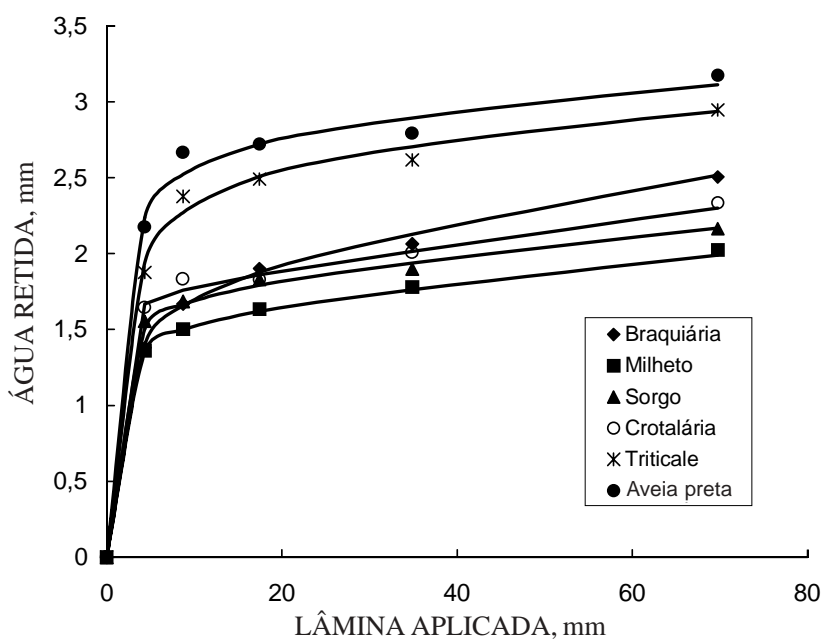

Figura 2. Retenção de água na palha, considerando as lâminas de chuva simulada.

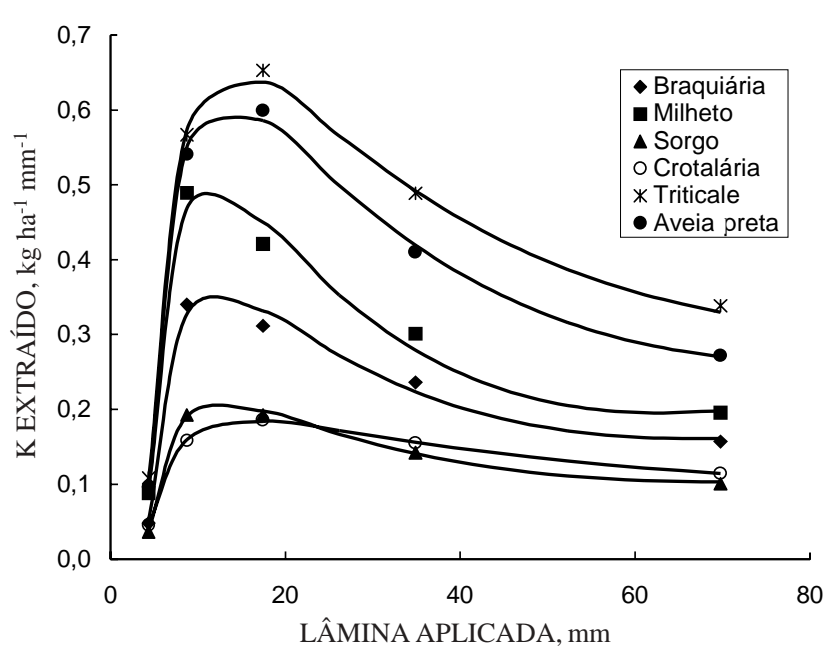

Figura 3. Potássio lixiviado por $\mathbf{m m}$ de chuva simulada.

Tanto os resultados obti dos para retenção de água na pal ha como para liberação de K devem estar na dependência da composição de cada espécie, que varia com relação aos teores de celulose, lignina e outros. Pode-se afirmar que o mecanismo regulador do processo éfísico, uma vez que a palha está morta e seca, não havendo tempo hábil para o desenvolvimento significativo de colônias de microrganismos que pudessem interferir no processo. A liberação de $\mathrm{K}$ por $\mathrm{mm}$ deágua aplicada diminui a partir do ponto em que as palhas ficaram saturadas (Figuras 2 e 3 ).

Assim, é possível estabelecer a seguintehipótese: quando a pal ha está seca, há, durante o processo de mol hamento, significativa difusão do K dos vacúolos, de modo a permitir sua lavagem. À medida que a palha fica saturada por água, deixa de ocorrer entrada e saída de umidade das palhas, ou seja, apenas a água que está na superfície é trocada pela água que está sendo aplicada. Por essa razão, o K que está no interior das células mortas precisa difundir-se até próximo à superfície, para ser então carregado pela chuva incidente. Assim, poderia ser feita uma analogia com a difusão efetiva de K em condições saturadas. A quantidade do nutriente liberada estaria então na dependência do teor na palha (poder-tampão) e do fator de tortuosidade (dependente da estrutura morfológica da espécie). Considerando esta hipótese como verdadeira, a intensi dade da chuva teria apenas um pequeno efeito no processo, pois estaria sendo renovada com mais intensi dadeapenas a água mais superficial da palha, com pouco efeito na difusão interna.

As curvas ajustadas para a lixiviação acumulada de K encontram-sena figura 4. A máxima lixiviação deK diferiu entreas espécies estudadas. O triticale ea aveia preta, por exemplo, com a aplicação de uma chuva de $69,8 \mathrm{~mm}$, liberaram mais $\mathrm{K}$ do que as demais espécies, com 23,5 e 18,9 kg ha-1, respectivamente, ao passo que o sorgo e a crotalária liberaram apenas 7,0 e 8,0 kg ha-1, corroborando os resultados da extração de $\mathrm{K}$ por unidade de chuva (Figura 3). I sso pode ser atribuído à maior concentração deste nutriente no tecido vegetal do triticale e da aveia, ou seja, 48,6 e 36,4 $\mathrm{g} \mathrm{kg}^{-1}$ de K, respectivamente (Figura 5).

Com relação à percentagem de $\mathrm{K}$ liberado da palha, o milheto foi a espécie de maior potencial, atingindo valores próximos a 7,0\% do total de $\mathrm{K}$ contido no tecido vegetal (Figura 6). Em contrapartida, o sorgo liberou de sua palha apenas $4,0 \%$ do total de $\mathrm{K}$ acumulado. Entretanto, o triticale, liberando 5,5 \% do K acumulado, apresentou o maior resultado em termos de $\mathrm{kg} \mathrm{ha}^{-1}$ de $\mathrm{K}$ lixiviado. Pode-seafirmar, portanto, quea palha do triticaletem um potencial intermediário de liberação do nutriente, apesar da quantidade relativamente el evada de K percolado junto à água da chuva.

Segundo Malavolta (1980), mais de $80 \%$ do K encontra-se na forma solúvel na planta, sendo, portanto, passível delixiviação. Essa percentagem parece ser bem menor e depender da espécie, uma vez que a lixiviação, no presente experimento, variou de aproximadamente $4,0 \%$ a aproximadamente $7,0 \%$. Por outro lado, considerando as formas de $\mathrm{K}$ na planta (Marschner, 1995), percebeu-se que esse nutriente não mostra função estrutural, sendo encontrado em maior proporção nos vacúol os, razão por que os baixos val ores de extração observados no presente experimento não seriam esperados. U ma hipótese para explicar este resultado seria que as espécies com mais tecido de colmo do que folhas apresentariam maior retenção do nutriente. Assim, as células do colmo poderiam estar em um estádio mais avançado de lignificação, dificultando tanto a entrada deágua como a saída de potássio. Esteseria o efeito do fator de tortuosidade já referido. 


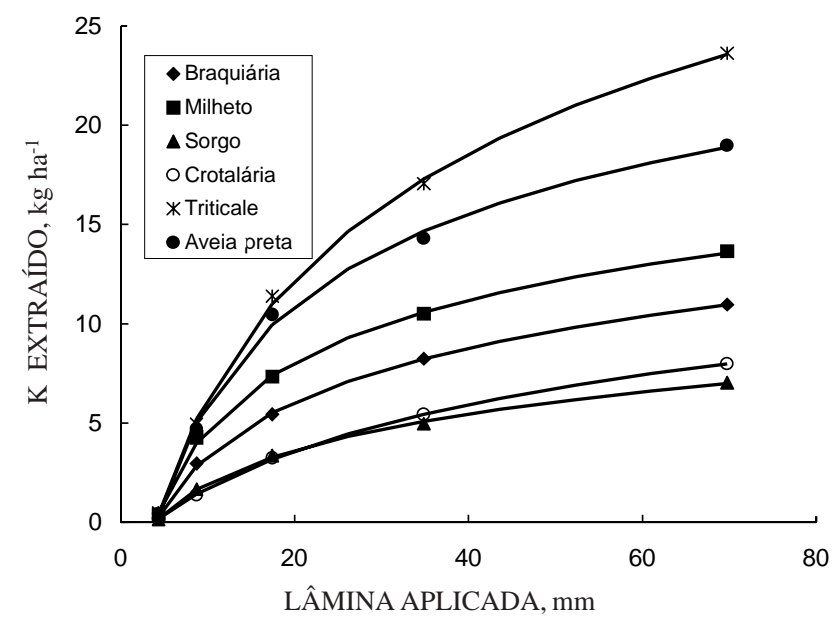

Figura 4. Lixiviação acumulada de potássio, considerando as lâminas de chuva simulada.

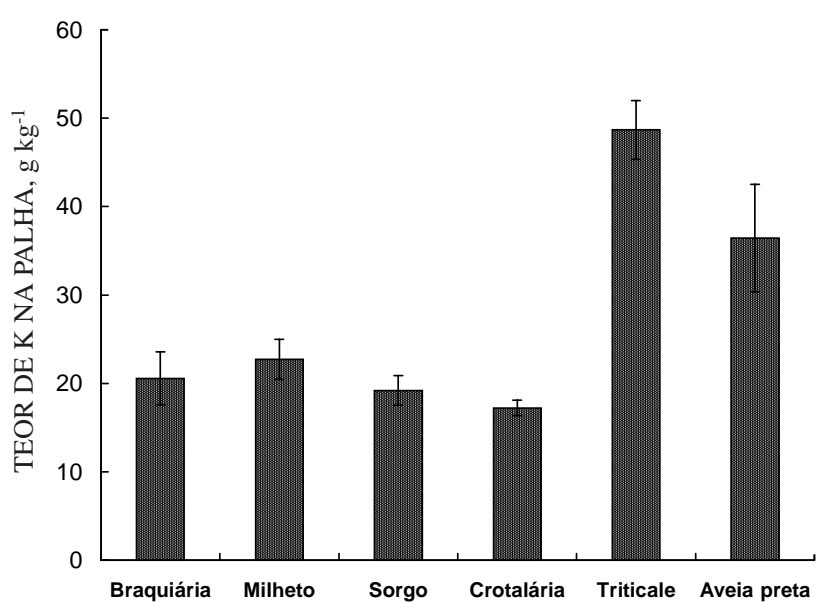

Figura 5. Concentração de potássio das palhas das seis espécies vegetais, antes de serem submetidas à si mulação de chuva.

É importante salientar que as espécies que acumularam mais $\mathrm{K}$ foram as que o liberaram em maior quantidade. Existem espécies com maior e outras com menor potencial de liberação imediata de K, o que foi detectado por meio do cál culo da percentagem deK extraído pelas chuvas em relação ao total do elemento contido nas palhas. A quantidade máxima de K lixiviado mostrou alta correlação positiva com o conteúdo de $\mathrm{K}$ da palha $(r=0,86, P<0,01)$, que, entretanto, não se correlacionou com a percentagem máxima de $\mathrm{K}$ liberado ( $r=0,06$, não-significativo). Esteresultado provavel mente ocorreu porque nas espécies quemais acumularam K, o nutriente, provavel mente, estava no vacúolo (Marschner, 1995), e, portanto, sua liberação, quando da dessecação da planta, ficou facilitada. Esta hipóteseé compatível coma analogia feita com a equação de difusão efetiva, já discutida, pois, neste caso, o poder-tampão deK estaria sendo diferente para cada espécie.

No que diz respeito ao aproveitamento de potássio pel as culturas em um sistema de rotação, a liberação diferenciada de $\mathrm{K}$ entre as espécies tem muito significado, pois algumas delas liberaram $\mathrm{K}$ numa intensidade bastante baixa, como é o caso da crotalária e do sorgo. O triticaleea aveia, por outro lado, disponibilizaram, de imediato, valores acima de $20 \mathrm{~kg} \mathrm{ha}^{-1}$ de $\mathrm{K}$, correspondendo a valores próximos de $25,0 \mathrm{~kg} \mathrm{ha}^{-1}$ de $\mathrm{K}_{2} \mathrm{O}$, num período em que a demanda da cultura subseqüente não é alta, podendo, portanto, ser suficiente para o início do seu crescimento.

Deve-se considerar que não haveria perigo de lixiviação do nutriente para as camadas mais profundas do solo, uma vez que, segundo Rosolem \& Nakagawa (1985), em sol os detextura leve, foram necessários mais de $80 \mathrm{~kg} \mathrm{ha}^{-1}$ de $\mathrm{K}_{2} \mathrm{O}$ por ano de cultivo, para proporcionar um aumento significativo na lixiviação de $K$.

Por outro lado, considerando que em 55 dias poderia haver liberação de praticamente todo o K do tecido (Cottica et al., 1999; Marcon et al., 1999), espécies como o sorgo e a crotalária, com menor liberação imediata do K, poderiam ser mais interessantes, dependendo do período decorrido entre o manejo das espécies de cobertura e a semeadura da cultura subseqüente.

Esses resultados discordam das observações feitas por Moraes \& Arens (1969) e por Rosolem (1997), que destacaram a facilidade de liberação de $K$, mas concordam no sentido de que a liberação depende, dentre outros fatores, do regime dechuvas. Embora Malavolta (1980) tenha relatado que $80 \%$

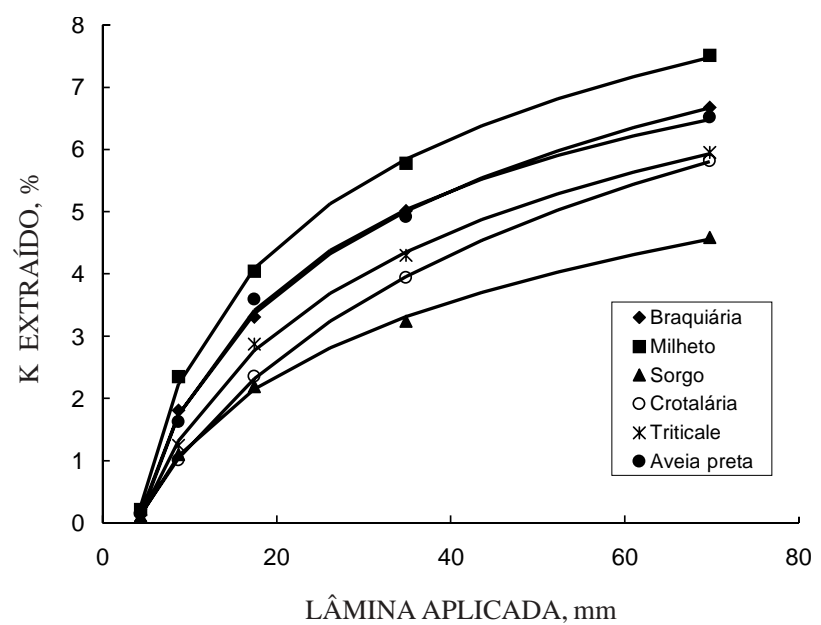

Figura 6. Percentagem de potássio lixiviado das palhas em relação ao total de $K$ acumulado no tecido das seis espécies vegetais. 
do $\mathrm{K}$ do tecido seria passível de lavagem, pelo fato de tal elemento encontrar-se quase que totalmente na forma solúvel, os resultados deste experimento mostram que essa lavagem depende também de outros fatores, além da chuva. Provavelmente, a maior liberação do $K$ dependetambém da degradação da palha, que não foi considerada nestetrabalho. A degradação biológica da palha implicaria rompimento das barreiras à difusão do K, facilitando sua liberação. I sto pode ter um importante significado ecológico na reciclagem denutrientes ena fertilização das camadas superficiais do solo.

Cottica et al. (1999) e Marcon et al. (1999) notaram, em condições de campo, que, passados 55 dias do manejo da aveia preta e do nabo forrageiro, houve perdas de 92 e $99 \%$ do K, respectivamente. No entanto, os autores não fazem referência à quantidade de chuva no período. Os resultados do presente experimento mostram que, além do tempo de exposição, a quantidade de chuva recebida pela palha também é importante, assim como a espécie. Embora testes preliminares tenham levado à inferência de que a intensidade da chuva não seja tão importante, o equipamento utilizado no presente experimento não permite que se faça, com segurança, considerações a respeito do efeito deste fator, o que exigiria experimento específico.

Com relação à prática da adubação potássica, é importante que se conheça o histórico de manejo das plantas de cobertura, bem como a precipitação pluviométrica ocorrida entreo manejoe a semeadura da cultura subseqüente, uma vez que a quantidade de $\mathrm{K}$ que poderá ser liberada da palha e estar prontamente disponível depende da espécie e da quantidade de chuva recebida, podendo ser considerável frenteàs doses de adubo normal mente recomendadas.

\section{CONCLUSÕES}

1. Chuvas inferiores a 5,0 mm praticamente não lixiviam $K$, uma vez que a palha retém até o equivalente a uma lâmina de 3,0 mm.

2. A taxa máxima de liberação de $\mathrm{K}$ depende muito da espécie, variando de 200 a $650 \mathrm{~g} \mathrm{ha}^{-1} \mathrm{~mm}^{-1}$, com chuvas entre 10 e 20 mm, decrescendo a partir deste ponto.

3. A quantidade deK liberado logo após o manejo das espécies de cobertura é relativamente baixa e correlaciona-se positivamente com a concentração do nutriente na palha.

4. Do ponto de vista deaproveitamento do K pela cultura seguinte, o triticale e a aveia seriam mais eficientes, pois disponibilizariam, logo após o manejo, maior quantidade do nutriente que as outras espécies.

\section{LITERATURA CITADA}

COTTICA, R.L.; PESSOA, A.C.S.; CRUSCIOL, C.A.C.; MARCON, E.; MORO, E. \& SOUZA, M.A. Persistência de cobertura morta e liberação de nutrientes de palhada de aveia preta em Latossolo Roxo cultivado com milho em plantio direto. In: CONGRESSO BRASILEIRO DE CIÊNCIA DO SOLO, 27., Brasília, 1999. Programas eResumos. Viçosa, Sociedade Brasileira de Ciência do Solo, 1999.

EMPRESA BRASILEIRA DE PESQUISA AGROPECUÁRIA EMBRAPA. Centro Nacional de Pesquisa da Soja. Recomendações técnicas para a cultura da soja na região central do Brasil (1997/1998). Londrina, 1997. 171p. (EMBRAPA-CNPSo. Documentos, 106)

EMPRESA BRASILEIRA DE PESQUISA AGROPECUÁRIA EMBRAPA. CentroNacional de Pesquisa de Solos. Sistema Brasileiro de Classificação de Sol os. Rio deJ aneiro, 1999. 412p.

GASSEN, D.N. \& GASSEN, F.R. Plantio direto. Passo Fundo, Aldeia Sul, 1996. 207p.

MACIEL, C.D.G. Simulação do caminhamento de herbicidas em diferentes tipos e quantidades de palhas utilizadas no sistema de plantio direto. Botucatu, Universidade Estadudal Paulista, 2001. 89p. (Tese de Mestrado)

MALAVOLTA, E.A. Elementos de nutrição mineral de plantas. São Paulo, Ceres, 1980. 251p.

MALAVOLTA, E.A.; VITTI, G.C. \& OLIVEIRA, S.A. Avaliação do estado nutricional das plantas: princípios e aplicações. Piracicaba, POTAFOS, 1997. 201p.

MARCON, E.; PESSOA, A.C.S.; CRUSCIOL, C.A.C.; COTTICA, R.L.; MORO, E. \& MÂNICA, M. Persistência e liberação de nutrientes de palhada de nabo forrageiro em condições de lavoura. In: CONGRESSO BRASILEIRO DE CIÊNCIA DO SOLO, 27., Brasília, 1999. Programa eResumos. Viçosa, Sociedade Brasileira de Ciência do Solo, 1999.

MARSCHNER, H. Mineral nutrition of higher plants. London, Academic Press, 1995. 889p.

MORAES, J.A.P. \& ARENS, K. Eliminação de potássio pelas fol has em dependência da luz e obscuridade (N ota preliminar). Ci. Cult., 21:728-30, 1969.

RAIJ , B. van \& QUAGGIO, J.A. Métodos de análise de solo para fins de fertilidade. Campinas, Instituto Agronômico, 1983. 31p.

RAIJ , B. van; CANTARELLA, H.; QUAGGIO, J .A. \& FURLANI, A.M.C., eds. Recomendações de adubação e calagem para o estado de São Paulo. 2.ed. Campinas, Instituto Agronômico \& Fundação IAC, 1996. 285p.

ROSOLEM, C.A. Adubação potássica em semeadura direta. In: SIMPÓSIO SOBRE FERTILIDADE DO SOLO EM PLANTIO DIRETO, Dourados, 1997. Resumos e Palestras. Dourados, Empresa Brasileira de Pesquisa Agropecuária, 1997. 12p.

ROSOLEM, C.A. \& NAKAGAWA, J. Potassium uptake by soybean as affected by exchangeable potassium in soil. Comm. Soil Sci. Plant Anal., 16:707-26, 1985.

SI LVA, M.A.S. Depósitos da cal da de pulverização no solo e em plantas de tiririca (Cyperus rotundus L.) em diferentes condições de aplicação. Botucatu, Universidade Estadual Paulista, 2000. 57p. (Tese de Doutorado) 